\title{
Evaluation of biological, psychosocial, and interventional predictors for success of a smoking cessation programme in Hong Kong
}

\author{
KS Ho *, Bandai WC Choi, Helen CH Chan, KW Ching
}

\section{A B S T R A C T}

Introduction: Predictors for smoking cessation have been identified in different studies but some of the predictors have been variable and inconsistent. In this study, we reviewed all the potential variables including medication, counselling, and others not commonly studied to identify the robust predictors of smoking cessation.

Methods: This historical cohort study was conducted in smoking cessation clinics in Hong Kong. Subjects who volunteered to come for free treatment between January 2010 and December 2011 were reviewed. Those under the age of 18 years, or who were mentally unstable or cognitively impaired were excluded. Counselling and quit-smoking medications were provided to the participants. The outcome measure was self-reported 7-day point prevalence abstinence rate at week 26 .

Results: Univariate analysis showed that the following were significant predictors of quitting: (1) psychosocial variables such as feeling stressed, feeling depressed, confidence in quitting, difficulty in quitting, importance of quitting, Smoking SelfEfficacy Questionnaire score; (2) smoking-related variables such as number of cigarettes smoked per day, Fagerström Test for Nicotine Dependence score, number of high-risk situations encountered; (3)

This article was published on 20 Nov 2015 at www.hkmj.org. health-related variable of having mental illness; (4) basic demographics such as age, marital status, and

household income; and (5) interventional variables such as counselling and pharmacotherapy. Multiple logistic regression showed that the independent predictors were age, having mental illness, daily cigarette consumption, Fagerström Test for Nicotine Dependence score, reasons for quitting, confidence in quitting, depressed mood, external self-efficacy, intervention with counselling and medications.

Conclusions: This clinic-based local study offers a different perspective on the predictors of quitting. It reminds us to adopt a holistic approach to deal with nicotine withdrawal, to enhance external selfefficacy to resist temptation and social influences, to provide adequate counselling, and to help smokers to cope with mood problems.

\section{Hong Kong Med J 2016;22:158-64}

DOI: $10.12809 / \mathrm{hkmj} 154549$

KS Ho *, FHKAM (Family Medicine), FHKAM (Medicine)

BWC Choi, MSocSc

HCH Chan, MSocSc, MPH

KW Ching, MB, BS, FHKAM (Family Medicine)

Integrated Centre for Smoking Cessation, Tung Wah Group of Hospitals; (c/o) 17/F Tung Sun Commercial, 194-200 Lockhart Road, Wanchai, Hong Kong

* Corresponding author: rayhoks@yahoo.com.hk

New knowledge added by this study

- A more holistic list of predictors of smoking cessation were included in this local clinic-based study, and differed from many other studies by population survey. Household income, marital status, gender, years of smoking, smoking cohabitant, perceived health, anxious mood, perceived importance, and difficulty in quitting were no longer predictors. Many of these are not modifiable. It is more important to enhance self-efficacy and to use counselling and medication to counter mood problems.

Implications for clinical practice or policy

- In clinical practice, we should adopt a holistic approach to smoking cessation by providing more intensive counselling, managing withdrawal symptoms with medication, strengthening external self-efficacy to resist external temptation, and screening for mood problems.

\section{Introduction}

Smoking has long been identified as a major global public health issue. It is the leading cause of preventable death worldwide and kills about 6 million people each year. ${ }^{1}$ Although Hong Kong has the lowest smoking prevalence among the major cities of China, at $11.1 \%$ as reported in 2010 , it still accounts for about 5700 deaths annually, approximately one fifth of all deaths per year. In 1998, there were 1324 passive smoking-related deaths reported. ${ }^{2,3}$ 
According to the evidence-based MPOWER measures introduced by the World Health Organization ${ }^{4}$ to reduce the demand for tobacco, to provide smoking cessation services and cessation support in the public health care system, governments around the world have put more emphasis on smoking cessation programmes to reduce the tobacco-related health risks. ${ }^{5}$ On 1 January 2007, the Hong Kong Special Administrative Region (SAR) Government enacted the Smoking (Public Health) Ordinance and on 25 February 2009, tobacco tax was increased by $50 \%$. In 2009, the Tung Wah Group of Hospitals (TWGHs) was commissioned by the Hong Kong SAR Government to provide a communitybased smoking cessation service in Hong Kong.

The Integrated Centre on Smoking Cessation (ICSC) of the TWGHs was set up in different districts of Hong Kong, namely Shatin, Kwun Tong, Sheung Shui, Tuen Mun, Mongkok, Wanchai, Cheung Sha Wan, and Tsuen Wan to provide a free smoking cessation service to Hong Kong citizens. An integrated model of counselling and pharmacotherapy was adopted. ${ }^{6,7}$

Identification of predictors and determinants of success in smoking cessation is crucial for smoking cessation service. ${ }^{8}$ Over the last decade, health care professionals have endeavoured to identify the predictors and characteristics of successful quitters. ${ }^{9}$ Overseas studies have identified the following: old age, high socio-economic status, ${ }^{10-12}$ male gender, younger age at smoking initiation, previous quit attempts, being married, fewer depressive symptoms, fewer anxiety symptoms, lower prior tobacco consumption, lower score of Fagerström Test for Nicotine Dependence (FTND), no cohabitating smoker, and high cessation-related motivation/confidence. ${ }^{8,10-14}$ Nonetheless, many studies have shown that these predictors are not always consistent. ${ }^{11,15}$ This may be due to different methodologies and environments in different studies. Some studies were population surveys based on individual recall and did not include interventions. In this study, we analysed all potential variables and interventions. With a more comprehensive list of variables, we hoped to identify some robust independent predictors of successful quitters.

\section{Methods}

\section{Study setting}

Clients who attended an ICSC in different districts in Hong Kong from 1 January 2010 to 31 December 2011 were recruited via smoking cessation hotlines, referral from health care professionals, or selfreferral.

All clients received counselling, and pharmacotherapy was prescribed if the client agreed. An average of four face-to-face counselling sessions

\section{要成功推行戒煙計劃在生理 、心理和干預方面 預測因素的評估 \\ 何健生、蔡華智、陳靜嫻、程錦榮}

引言: 不同研究發現多項預測成功戒煙的因素, 但部分因素並不一致 且有很大差異。本研究探討所有包括藥物治療、心理輔導和其他不常 用的潛在變量, 以確定能預測成功戒煙的因素。

方法: 這項歷史隊列研究在香港的戒煙診所進行。於 2010 年 1 月至 2011 年 12 月期間自願接受免費戒煙治療的參與者均被納入研究範圍。 本研究不包括 18 歲以下、精神狀態不穩定或有認知障礙的人士。研究 期間會為參與者提供戒煙輔導和戒煙的藥物。研究的主要結果測量是 在第 26 週時得出的自我報告成功戒煙率, 即在過去七天內完全沒有吸 煙。

結果：單變量分析顯示以下均為預測成功戒煙的因素：(1) 心理變 量：如感到有壓力、心情鬱悶、戒煙的信心、戒煙的困難、戒煙的重 要性和吸煙自我效能問卷得分; (2) 與吸煙相關的變量 : 如每天吸 煙數量、Fagerström尼古丁依賴測試分數和遇上高風險情況的次數 ; （3）與精神健康有關的變量;（4）基線人口特徵：如年齡、婚姻 狀況和家庭收入; 以及（5) 介入變量：如輔導和藥物治療。多元邏 輯迴歸分析顯示獨立的預測因素為年齡、有精神障礙、每天吸煙數 量、Fagerström得分、放棄戒煙的原因、戒煙的信心、低落的情緒、 外部自我效能、戒煙輔導和戒煙藥物治療。

結論：本研究在診所內進行, 並從不同角度提供有關成功戒煙的預測 因素。研究結果提醒我們須採取全面的措施來戒斷尼古丁以抗拒誘惑 和社會影響的外部自我效能, 提供合適的戒煙輔導, 並幫助吸煙者應 付情緒問題。

were conducted over the first 8-week intensive treatment phase by registered social workers who were all trained in tobacco cessation counselling. Phone follow-up and counselling were also offered during this treatment phase and between 9 and 12 weeks. The stage of change theory and motivational interviewing techniques were adopted. ${ }^{16-18}$ Clients were followed up by telephone at week 26 and week 52 to ascertain abstinence from smoking. The medications provided by ICSC included nicotine replacement therapy (NRT) and non-NRT. The former included nicotine patches, gum, lozenges, and inhalers. Oral medications included varenicline and bupropion. Medications were prescribed according to the clients' personal preference and clinical conditions following a thorough explanation by counsellors or medical officers. For example, NRT gum would not be given to a client with dentures and a patch would not be given to a client with skin allergy.

\section{Study design, participants, and data collection}

This was a historical cohort study. All cases commenced treatment between 1 January 2010 and 
31 December 2011. The inclusion criteria of the study were adults aged 18 years or above. Clients who were mentally unstable or cognitively impaired were excluded.

A structured questionnaire was used to collect the following information: (i) socio-demographic variables: age, gender, marital status, education, monthly household income, number of people living together; (ii) health-related variables: perceived health, cessation advice by nurse, cessation advice by doctor, cessation advice by any medical professional, severe/chronic illness, mental illness; (iii) smokingrelated variables: age started smoking, years of smoking, cohabitation with another smoker, number of cigarettes smoked per day, FTND score, ${ }^{19}$ previous quit attempt, number of previous quit attempts, time of last attempt, reason to quit, high-risk situation; (iv) psychosocial variables: self-perceived stress, self-perceived depression, perceived importance, difficulty and confidence in quitting (from a scale of 0-100), perceived source of social support, Smoking Self-Efficacy Questionnaire (SEQ-12) ${ }^{20,21}$; and (v) intervention variables. Consent was obtained and confidentiality was assured. The questionnaire was self-administered and illiterate clients were given help as appropriate. Completed forms were validated by the counsellors.

\section{Outcome measure}

The outcome measure was self-reported 7-day point prevalence abstinence rate at week 26 . Clients who were not able to be followed up or with an absent response for smoking status were considered to have not quitted.

\section{Statistical analyses}

Data management and analysis was performed using the Statistical Package for the Social Sciences (Windows version 22.0; SPSS Inc, Chicago [IL], US). Univariate logistic regression was used for all studied predictors. All predictors with a reported $\mathrm{P}$ value of $<0.10$ were then included in multiple logistic regression analysis. Backward elimination was used in the multivariate analysis to identify independent predictors of abstinence as well as to calculate the adjusted odds ratio (AOR) and 95\% confidence interval. All statistical analyses were two-tailed tests and a $P$ value of $<0.05$ was considered statistically significant.

\section{Results \\ Demographics}

A total of 4045 clients who attended the ICSC during 1 January 2010 to 31 December 2011 were reviewed and 3853 cases who met the inclusion criteria were analysed. The gender ratio of male-to-female was approximately 7:3. Their age ranged from 18 to
89 years with a mean of 42 years; mean duration of smoking of this cohort was 20 years, and mean cigarette consumption was 18 cigarettes per day (Table 1).

\section{Univariate logistic regression}

The abstinence rate at week 26 was $35.1 \%$ (1353/3853). Univariate analysis of basic demographic data revealed that successful quitting was related to

TABLE I. Demographics and smoking-related characteristics of subjects $(n=3853)$

\begin{tabular}{|c|c|}
\hline & Data* $^{*}$ \\
\hline \multicolumn{2}{|l|}{ Demographic variables } \\
\hline Age (years) & $42.2 \pm 12.2$ \\
\hline \multicolumn{2}{|l|}{ Gender } \\
\hline Male & $2740(71.1)$ \\
\hline Female & $1113(28.9)$ \\
\hline \multicolumn{2}{|l|}{ Marital status $\dagger$} \\
\hline Single & 1146 (29.9) \\
\hline Married/cohabited & $2220(57.8)$ \\
\hline Separated/divorced/widowed & $472(12.3)$ \\
\hline \multicolumn{2}{|l|}{ Education† } \\
\hline Primary school or below & $410(11.2)$ \\
\hline Form 1 to Form 3 & $1067(29.1)$ \\
\hline Form 4 to Form 7 & $1670(45.6)$ \\
\hline Post secondary or tertiary & $516(14.1)$ \\
\hline \multicolumn{2}{|l|}{ Monthly household income (HK\$) } \\
\hline$<10000$ & $1031(26.8)$ \\
\hline $10000-19999$ & $1129(29.3)$ \\
\hline $20000-29999$ & $642(16.7)$ \\
\hline$\geq 30000$ & 575 (14.9) \\
\hline Not disclosed & $476(12.4)$ \\
\hline No. of people in household $†$ & $2.9 \pm 1.4$ \\
\hline \multicolumn{2}{|l|}{ Smoking-related characteristics } \\
\hline Age started smoking (years) $†$ & $20.2 \pm 7.7$ \\
\hline Time as daily smoker (years) $\dagger$ & $21.9 \pm 11.9$ \\
\hline \multicolumn{2}{|l|}{ Any cohabited smokers $\dagger$} \\
\hline Yes & $725(20.5)$ \\
\hline No & 2815 (79.5) \\
\hline No. of cigarette(s) per day† & $18.2 \pm 9.2$ \\
\hline \multicolumn{2}{|l|}{ FTND score† } \\
\hline Low $(0-3)$ & $777(20.2)$ \\
\hline Medium (4-5) & $998(26.0)$ \\
\hline High (6-10) & $2064(53.8)$ \\
\hline
\end{tabular}

Abbreviation: FTND = Fagerström Test for Nicotine Dependence

* Data are shown as mean \pm standard deviation or No. (\%) of participants

† Some cases have missing field (range, 14-339), and the \%s displayed are based on available cases only 
older age, being married, and higher household income (Table 2). Mental illness was significantly related to failure to quit but chronic illness was not, for examples, hypertension, diabetes, and chronic obstructive pulmonary disease.

Analysis of smoking-related variables showed that successful quitting was related to longer years of smoking, not cohabiting with a smoker, lower daily cigarette consumption, and lower FTND score. Successful quitters were more likely to report "prove my ability to quit smoking" and "avoid discrimination as a smoker". A higher number of high-risk situations in quitting were negatively related to quit rate. Significant individual high-risk situations included "under time pressure", "arguing with others", "depressed or frustrated", "drinking alcohol or coffee", "difficulty in sleeping", and "bored" (Table 3).

The following psychosocial variables were correlated to quitting: not feeling stressed, not feeling depressed, high perceived importance of quitting, low perceived difficulty in quitting, high confidence in quitting, perceived support from spouse, and high SEQ-12 score (Table 4). All interventional variables were significant predictors of smoking abstinence: number of face-to-face counselling sessions, overthe-phone counselling, and use of medication.

\section{Multiple logistic regression}

All items reported $\mathrm{P}<0.10$ in the univariate logistic regression analysis were included in the multiple logistic model with backward elimination. Only subjects with complete data in all fields of the included items were analysed $(\mathrm{n}=2714)$. As shown in Table 5, independent predictors of smoking abstinence at week 26 were older age, quitting based on "prove my ability to quit smoking", high confidence in quitting, high external self-efficacy, more counselling sessions (both office and phone contact), and use of medication. The following characteristics were predictive of failure to quit: history of mental illness, high daily cigarette consumption, high FTND score, and feeling depressed.

\section{Discussion}

This is the first comprehensive study of predictors of success for smoking cessation in a local smoking cessation service. Age, mental health, cigarette consumption, FTND score, reasons to quit, confidence in quitting, depressive mood, self-efficacy, sessions of office counselling, phone counselling, and medication treatment were identified as predictors among clients who volunteered to quit smoking.

In the univariate logistic analysis, most of the predictors were consistent with other studies. In many studies of predictors, ${ }^{15,22}$ results for gender, number of previous attempts, education level and social status, years of smoking, and history of depression have been inconsistent. In our study, a more comprehensive list of potential predictors from five domains (namely, demographics, health-related, smoking-related, psychosocial, and interventional variables) was included. After multiple logistic regression analysis, many commonly reported determinants/predictors were excluded. They included perceived health, marital status, cohabitation with a smoker, household income, gender, years of smoking, perceived importance of

TABLE 2. Univariate logistic regression analysis of socio-demographic and healthrelated variables $(n=3853)$

\begin{tabular}{|c|c|c|c|}
\hline Variable & Crude OR & $95 \% \mathrm{Cl}$ & $P$ value \\
\hline \multicolumn{4}{|l|}{ Socio-demographic variable } \\
\hline Age & 1.01 & $1.01-1.02$ & $<0.001$ \\
\hline \multicolumn{4}{|l|}{ Marital status ${ }^{\star}$} \\
\hline Separated/divorced/widowed & 1 & Referent & \\
\hline Married/cohabited & 1.39 & $1.13-1.73$ & 0.001 \\
\hline \multicolumn{4}{|l|}{ Monthly household income (HK\$) } \\
\hline$<10000$ & 1 & Referent & \\
\hline$\geq 30000$ & 1.34 & $1.08-1.65$ & 0.008 \\
\hline \multicolumn{4}{|l|}{ Health-related variable } \\
\hline Reported having mental illness* & 0.54 & $0.44-0.66$ & $<0.001$ \\
\hline
\end{tabular}

Abbreviations: $\mathrm{Cl}=$ confidence interval; $\mathrm{OR}=$ odds ratio

* Data were missing in this item (range, 15-74)

TABLE 3. Univariate logistic regression analysis of smoking-related variables $(n=3853)$

\begin{tabular}{lccc}
\hline Smoking-related variable & Crude OR & 95\% CI & P value \\
\hline Years of smoking* & 1.01 & $1.01-1.02$ & $<0.001$ \\
\hline Have cohabited smoker* & 0.82 & $0.69-0.97$ & 0.024 \\
\hline No. of cigarette(s) per day* & 0.98 & $0.97-0.99$ & $<0.001$ \\
\hline FTND score* & & & \\
\hline Low (0-3) & 1 & Referent & \\
\hline Medium (4-5) & 0.80 & $0.66-0.97$ & 0.024 \\
\hline High (6-10) & 0.60 & $0.51-0.71$ & $<0.001$ \\
\hline Reasons to quit & & & \\
\hline Prove my ability to quit smoking & 1.25 & $1.08-1.46$ & 0.003 \\
\hline Avoid discrimination as a smoker & 1.33 & $1.07-1.67$ & 0.012 \\
\hline Perceived high-risk situation & & & \\
\hline Under time pressure & 0.72 & $0.61-0.86$ & $<0.001$ \\
\hline Arguing with others (feeling irritated/angry) & 0.83 & $0.71-0.97$ & 0.017 \\
\hline Depressed or frustrated & 0.85 & $0.74-0.98$ & 0.027 \\
\hline Drinking alcohol or coffee & 0.82 & $0.71-0.96$ & 0.011 \\
\hline Difficulty in sleeping & 0.75 & $0.62-0.89$ & 0.001 \\
\hline Bored & 0.77 & $0.67-0.89$ & $<0.001$ \\
\hline No. of perceived high-risk situations & 0.94 & $0.92-0.97$ & $<0.001$ \\
\hline Abbritions: Cl con & & & \\
\hline
\end{tabular}

Abbreviations: $\mathrm{Cl}=$ confidence interval; FTND = Fagerström Test for Nicotine

Dependence; $\mathrm{OR}=$ odds ratio

* Data were missing in this item (range, | |-3|3) 
TABLE 4. Univariate logistic regression analysis of psychosocial and interventional variables $(n=3853)$

\begin{tabular}{|c|c|c|c|}
\hline Variable & Crude OR & $95 \% \mathrm{Cl}$ & $P$ value \\
\hline \multicolumn{4}{|l|}{ Psychosocial variable } \\
\hline Felt stressed* & 0.71 & $0.62-0.81$ & $<0.001$ \\
\hline Felt depressed* & 0.76 & $0.66-0.88$ & $<0.001$ \\
\hline Importance of quitting $(0-100)^{*}$ & 1.01 & $1.00-1.01$ & 0.001 \\
\hline Difficulty in quitting $(0-100)^{*}$ & 0.99 & $0.99-1.00$ & 0.002 \\
\hline Confidence in quitting $(0-100)^{\star}$ & 1.01 & $1.01-1.02$ & $<0.001$ \\
\hline \multicolumn{4}{|l|}{ Perceived social support } \\
\hline Spouse & 1.15 & $1.01-1.32$ & 0.035 \\
\hline \multicolumn{4}{|l|}{ Self-efficacy } \\
\hline Self-efficacy (total) ${ }^{\star}$ & 1.02 & $1.01-1.02$ & \\
\hline Self-efficacy (external)* & 1.02 & $1.01-1.03$ & $<0.001$ \\
\hline Self-efficacy (internal)* & 1.03 & $1.02-1.04$ & $<0.001$ \\
\hline \multicolumn{4}{|l|}{ Interventional variable } \\
\hline No. of face-to-face counselling* & 1.20 & $1.17-1.24$ & $<0.001$ \\
\hline No. of over-the-phone counselling ${ }^{*}$ & 1.10 & $1.07-1.13$ & $<0.001$ \\
\hline \multicolumn{4}{|l|}{ Drug used* } \\
\hline No drug used & 1 & Referent & \\
\hline NRT & 3.20 & $2.64-3.89$ & $<0.001$ \\
\hline Non-NRT & 3.39 & $2.21-5.21$ & $<0.001$ \\
\hline
\end{tabular}

Abbreviations: $\mathrm{Cl}=$ confidence interval; NRT = nicotine replacement therapy; $\mathrm{OR}=$ odds ratio

* Data were missing in this item (range, 7-3II)

quitting or difficulty in quitting, feeling anxious, and internal self-efficacy in quitting.

The effect of age appeared to be consistent with the results of local ${ }^{23,24}$ and some international studies $^{11-13}$ that older age was an independent predictor. ${ }^{25}$ Results for the predictive power of male gender have been controversial: some studies have reported it as a predictor of cessation success, ${ }^{8,10,26}$ while others have found it to have no significant effect or a negative effect. ${ }^{12,27,28}$ Our study could not confirm these findings. In addition, the role of marital status, education, household income, and number of cohabitants were shown not to be predictive, contrary to some overseas studies..$^{29,30}$ Nonetheless, consistent with many studies, cigarette consumption and FTND score were negatively correlated with quit rate. ${ }^{8,27,31}$

Extensive research indicates that individual motivation, especially intrinsic motivation, is predictive of the long-term cessation result. ${ }^{8}$ In our study, two robust reasons to quit that could significantly predict abstinence were "prove my ability to quit smoking" and "avoid discrimination as a smoker". This seemed to correspond to the "selfcontrol" and "social influence" factors of Reasons for Quitting scale. ${ }^{32}$ In Hong Kong, smoking in some designated areas and public places is forbidden.
This may precipitate the "avoid discrimination as a smoker" response. In service provision, operational initiatives and promotion strategies may be tailored to these two areas when motivating smokers to quit.

Perceived depressive mood (AOR=0.77) and history of mental illness $(\mathrm{AOR}=0.67)$ greatly enervated the success rate of quitting in our participants. Similar results have been reported in western countries as well as in Asia. ${ }^{8,33-35}$ This reinforces the importance of implementing appropriate mental health screening and referral in smoking cessation clinics. Presence of a chronic illness was not shown to be predictive although this may have been due to our relatively small sample size for this group of clients or because ours was a cohort of smokers who were motivated to quit. The effect of chronic illness may thus be attenuated. Studies have also shown that not all chronic diseases have the same impact on smoking cessation. ${ }^{36,37}$

The link between self-efficacy and successful quitting has long been established. ${ }^{22,38}$ Both external and internal self-efficacy in SEQ-12 scales have been found to be predictive in smoking cessation in western countries. ${ }^{21}$ In our study, after adjusting all potential predictors, a high degree of confidence and external self-efficacy were predictive of cessation, while the predictive ability of total and internal sub-score of SEQ-12 faded after adjustment. This is consistent with a previous Hong Kong study. ${ }^{20}$ Manifestation of cultural differences in self-efficacy during smoking cessation warranted further investigation. According to the results in the current study, smoking cessation counselling should focus more on helping clients to develop techniques to resist external temptation and to enhance external self-efficacy.

Consistent with overseas reviews of smoking cessation counselling, ${ }^{15,39}$ our study indicated that the number of sessions of face-to-face counselling or phone support were strong predictors $(\mathrm{AOR}=1.15$ and 1.12 , respectively). Both kinds of medication (NRT and non-NRT) were also associated with successful smoking cessation. Most previous predictor studies have not included these parameters, however.

There are some limitations in our study. Since this was a retrospective case review study of smokers who were motivated to quit, the results cannot be generalised to the whole smoking population. In addition, in the process of multiple logistic regression, only 2714 clients instead of all study subjects were analysed. Interventional variables such as office counselling, phone counselling, and medication modality were not randomly allocated. Patient compliance with medication was not evaluated, thus information on the use of medication may be biased. Another potential confounding factor was a small amount of missing data for some predictors. The effect of job nature and different chronic illnesses was not included in this study because of insufficient 
TABLE 5. Multiple logistic regression $(n=27 \mid 4)$

\begin{tabular}{|c|c|c|c|c|}
\hline Variable & Adjusted OR & Adjusted OR of 1 SD (SD) & $95 \% \mathrm{Cl}$ & $P$ value \\
\hline \multicolumn{5}{|l|}{ Demographic } \\
\hline Age & 1.01 & $1.12(12.2)$ & $1.00-1.02$ & 0.025 \\
\hline \multicolumn{5}{|l|}{ Health-related } \\
\hline Reported having mental illness & 0.67 & & $0.52-0.88$ & 0.003 \\
\hline \multicolumn{5}{|l|}{ Smoking-related } \\
\hline No. of cigarette(s) per day & 0.98 & $0.86(9.24)$ & $0.97-1.00$ & 0.008 \\
\hline \multicolumn{5}{|l|}{ FTND score } \\
\hline Low (0-3) & 1 & & Referent & \\
\hline Medium (4-5) & 0.79 & & $0.62-1.00$ & 0.054 \\
\hline High (6-10) & 0.68 & & $0.54-0.87$ & 0.002 \\
\hline \multicolumn{5}{|l|}{ Reason to quit } \\
\hline Prove my ability to quit smoking & 1.23 & & $1.11-1.49$ & 0.036 \\
\hline Avoid discrimination as a smoker & 1.39 & & $1.05-1.84$ & 0.023 \\
\hline \multicolumn{5}{|l|}{ High-risk situation } \\
\hline Time pressure & 0.84 & & $0.68-1.03$ & 0.096 \\
\hline Drinking alcohol or coffee & 0.84 & & $0.69-1.02$ & 0.071 \\
\hline \multicolumn{5}{|l|}{ Psychosocial } \\
\hline Confidence in quitting $(0-100)$ & 1.01 & $1.28(22.4)$ & $1.01-1.02$ & $<0.001$ \\
\hline Feel depressed & 0.77 & & $0.65-0.92$ & 0.004 \\
\hline Self-efficacy (external) & 1.01 & $1.10(6.98)$ & $1.01-1.03$ & 0.039 \\
\hline \multicolumn{5}{|l|}{ Interventional } \\
\hline No. of face-to-face counselling & 1.15 & & $1.11-1.20$ & $<0.001$ \\
\hline No. of over-the-phone counselling & 1.12 & & $1.08-1.17$ & $<0.001$ \\
\hline \multicolumn{5}{|l|}{ Drug used } \\
\hline No drug used & 1 & & Referent & \\
\hline NRT & 2.33 & & $1.81-3.01$ & $<0.001$ \\
\hline Non-NRT & 2.63 & & $1.56-4.43$ & $<0.001$ \\
\hline
\end{tabular}

Abbreviations: $\mathrm{Cl}=$ confidence interval; FTND = Fagerström Test for Nicotine Dependence; NRT = nicotine replacement therapy; $\mathrm{OR}=$ odds ratio; $\mathrm{SD}=$ standard deviation

data; only chronic disease as a group was analysed. holistic approach to the management of nicotine Self-reported 7-day point prevalence abstinence rate withdrawal, and to enhance external self-efficacy was not biochemically validated although previous and motivation, to provide an adequate number of study has shown that self-reported abstinence counselling sessions and to help smokers cope with does not differ much to abstinence according to mood problems. biochemical validation. ${ }^{40}$

\section{Conclusions}

This local study has identified a number of predictors of smoking abstinence at week 26 in clients who volunteered to seek treatment from a smoking cessation clinic. Most large-scale overseas studies have been based on a population survey. This was a large-scale comprehensive study performed in a real-life smoking cessation programme in Hong Kong. As such, it offers a better understanding of the determinants of successful quitting. Although some predictors have not been addressed and need further study, this study highlights the need for a

\section{References}

1. WHO Report on the global tobacco epidemic. Geneva: World Health Organization; 2013.

2. Lam TH, Ho SY, Hedley AJ, Mak KH, Peto R. Mortality and smoking in Hong Kong: case-control study of all adult deaths in 1998. BMJ 2001;323:361.

3. Hong Kong Council on Smoking and Health: Annual Report 2011-2012. Hong Kong: Hong Kong Council on Smoking and Health; 2012.

4. WHO Report on the global tobacco epidemic, 2008: The MPOWER Package. Geneva: World Health Organization; 2008.

5. Wang L, Kong L, Wu F, Bai Y, Burton R. Preventing chronic diseases in China. Lancet 2005;366:1821-4. 
6. 2008 PHS Guideline Update Panel, Liaisons, and Staff. Treating tobacco use and dependence: 2008 update U.S. Public Health Service Clinical Practice Guideline executive summary. Respir Care 2008;53:1217-22.

7. Reducing tobacco use: a report of the Surgeon Generalexecutive summary. Nicotine Tob Res 2000;2:379-95.

8. Caponnetto P, Polosa R. Common predictors of smoking cessation in clinical practice. Respir Med 2008;102:1182-92.

9. Prochaska JO, DiClemente CC, Velicer WF, Ginpil S, Norcross JC. Predicting change in smoking status for selfchangers. Addict Behav 1985;10:395-406.

10. Hymowitz N, Cummings KM, Hyland A, Lynn WR, Pechacek TF, Hartwell TD. Predictors of smoking cessation in a cohort of adult smokers followed for five years. Tob Control 1997;6 Suppl 2:S57-62.

11. Monsó E, Campbell J, Tønnesen P, Gustavsson G, Morera J. Sociodemographic predictors of success in smoking intervention. Tob Control 2001;10:165-9.

12. Osler M, Prescott E. Psychosocial, behavioural, and health determinants of successful smoking cessation: a longitudinal study of Danish adults. Tob Control 1998;7:262-7.

13. Hyland A, Borland R, Li Q, et al. Individual-level predictors of cessation behaviours among participants in the International Tobacco Control (ITC) Four Country Survey. Tob Control 2006;15 Suppl 3:iii83-94.

14. Haas AL, Muñoz RF, Humfleet GL, Reus VI, Hall SM. Influences of mood, depression history, and treatment modality on outcomes in smoking cessation. J Consult Clin Psychol 2004;72:563-70.

15. Iliceto P, Fino E, Pasquariello S, D’Angelo Di Paola ME, Enea D. Predictors of success in smoking cessation among Italian adults motivated to quit. J Subst Abuse Treat 2013;44:534-40.

16. Miller WR, Rollnick S. Talking oneself into change: motivational interviewing, stages of change, and therapeutic process. J Cogn Psychother 2004;18:299-308.

17. DiClemente CC, Prochaska JO. Toward a comprehensive, transtheoretical model of change: stages of change and addictive behaviors. In: Miller WR, Heather N, editors. Treating addictive behaviors. 2nd ed. New York: Plenum Press; 1998: 3-24.

18. Lai DT, Cahill K, Qin Y, Tang JL. Motivational interviewing for smoking cessation. Cochrane Database Syst Rev 2010;(1):CD006936.

19. Heatherton TF, Kozlowski LT, Frecker RC, Fagerström KO. The Fagerström Test for Nicotine Dependence: a revision of the Fagerström Tolerance Questionnaire. Br J Addict 1991;86:1119-27.

20. Leung DY, Chan SS, Lau CP, Wong V, Lam TH. An evaluation of the psychometric properties of the Smoking SelfEfficacy Questionnaire (SEQ-12) among Chinese cardiac patients who smoke. Nicotine Tob Res 2008;10:1311-8.

21. Etter JF, Bergman MM, Humair JP, Perneger TV. Development and validation of a scale measuring selfefficacy of current and former smokers. Addiction 2000;95:901-13.

22. Li L, Borland R, Yong HH, et al. Predictors of smoking cessation among adult smokers in Malaysia and Thailand: findings from the International Tobacco Control Southeast Asia Survey. Nicotine Tob Res 2010;12 Suppl:S34-44.

23. Yu DK, Wu KK, Abdullah AS, et al. Smoking cessation among Hong Kong Chinese smokers attending hospital as outpatients: impact of doctors' advice, successful quitting and intention to quit. Asia Pac J Public Health 2004;16:11520 .

24. Abdullah AS, Yam HK. Intention to quit smoking, attempts to quit, and successful quitting among Hong Kong Chinese smokers: population prevalence and predictors. Am J Health Promot 2005;19:346-54.

25. Fiore MC, Novotny TE, Pierce JP, Hatziandreu EJ, Patel KM, Davis RM. Trends in cigarette smoking in the United States. The changing influence of gender and race. JAMA 1989;261:49-55.

26. Piper ME, Cook JW, Schlam TR, et al. Gender, race, and education differences in abstinence rates among participants in two randomized smoking cessation trials. Nicotine Tob Res 2010;12:647-57.

27. Vangeli E, Stapleton J, Smit ES, Borland R, West R. Predictors of attempts to stop smoking and their success in adult general population samples: a systematic review. Addiction 2011;106:2110-21.

28. Bjornson W, Rand C, Connett JE, et al. Gender differences in smoking cessation after 3 years in the Lung Health Study. Am J Public Health 1995;85:223-30.

29. Kim YJ. Predictors for successful smoking cessation in Korean adults. Asian Nurs Res (Korean Soc Nurs Sci) 2014;8:1-7.

30. Chandola T, Head J, Bartley M. Socio-demographic predictors of quitting smoking: how important are household factors? Addiction 2004;99:770-7.

31. Abdullah AS, Ho LM, Kwan YH, Cheung WL, McGhee SM, Chan WH. Promoting smoking cessation among the elderly: what are the predictors of intention to quit and successful quitting? J Aging Health 2006;18:552-64.

32. Curry S, Wagner EH, Grothaus LC. Intrinsic and extrinsic motivation for smoking cessation. J Consult Clin Psychol 1990;58:310-6.

33. Kim SK, Park JH, Lee JJ, et al. Smoking in elderly Koreans: prevalence and factors associated with smoking cessation. Arch Gerontol Geriatr 2013;56:214-9.

34. Lasser K, Boyd JW, Woolhandler S, Himmelstein DU, McCormick D, Bor DH. Smoking and mental illness: A population-based prevalence study. JAMA 2000;284:260610.

35. Covey LS, Glassman AH, Stetner F. Depression and depressive symptoms in smoking cessation. Compr Psychiatry 1990;31:350-4.

36. Salive ME, Cornoni-Huntley J, LaCroix AZ, Ostfeld AM, Wallace RB, Hennekens $\mathrm{CH}$. Predictors of smoking cessation and relapse in older adults. Am J Public Health 1992;82:1268-71.

37. Freund KM, D'Agostino RB, Belanger AJ, Kannel WB, Stokes J 3rd. Predictors of smoking cessation: The Framingham Study. Am J Epidemiol 1992;15:957-64.

38. Gwaltney CJ, Metrik J, Kahler CW, Shiffman S. Selfefficacy and smoking cessation: a meta-analysis. Psychol Addict Behav 2009;23:56-66.

39. Clinical Practice Guideline Treating Tobacco Use and Dependence 2008 Update Panel, Liaisons, and Staff. A clinical practice guideline for treating tobacco use and dependence: 2008 update. A U.S. Public Health Service report. Am J Prev Med 2008;35:158-76.

40. Patrick DL, Cheadle A, Thompson DC, Diehr P, Koepsell T, Kinne S. The validity of self-reported smoking, a review and meta-analysis. Am J Public Health 1994;84:1086-93. 